\title{
СИСТЕМА КОНТРОЛЮ ГЕОМЕТРИЧНИХ ПАРАМЕТРІВ З'СДНАНЬ ПРИ ЛАЗЕРНОМУ ЗВАРЮВАННІ КРИВОЛІНІЙНИХ ДЕТАЛЕЙ
}

\author{
Червона T.B. ${ }^{1}$ \\ ${ }^{1}$ ПАТ «НВО «КЗА ім. Г.І. Петровського», Київ
}

Copyright (C 2014 by author and the journal “Automation technological and business - processes". This work is licensed under the Creative Commons Attribution International License (CC BY). http://creativecommons.org/licenses/by/4.0/

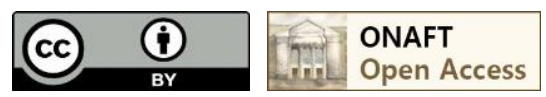

Анотація

Досліджувався вплив фокусування системи, коефіцієнта розсіювання на геометрію площі взаємодії лазерного випромінювання та металу під час імпульсного зварювання криволінійних деталей. Виділений емпіричний коефіцієнт, що дозволяс підвести теоретичну базу під фізичні процеси, що відбуваються при лазерному зварюванні різних типів сплавів.

\begin{abstract}
Focusing system and the scattering coefficient affects the shape of the interactions place of pulse welding laser radiation with metal. Empirical coefficient improved theoretical calculations to practical results
\end{abstract}

Ключові слова

Лазерне випромінювання, емпіричний коефіцієнт, фокусування оптичної системи, сплави металів, метрологічні параметри, коефіцієнт розсіювання лазерного випромінювання.

Актуальність теми визначається потребою у вдосконалені системи розрахунків можливого розсіювання лазерного випромінювання до здійснення пострілів імпульсами та контролі геометрії поверхні зварювального шва.

На сьогоднішній день проведені десятки досліджень параметрів лазерного випромінювання. Розроблені алгоритми вдосконалення оптичних систем квантових резонаторів. Виділивши основні задачі у промисловості, медицині та інших галузях підбираються оптичні квантові генератори 3 потрібними параметрами як лазерного випромінювання, так і лінз, дзеркал, їх взаємного розташування.

Основними проблемами вже певний час лишаються нестабільність просторова та температурна лазерного випромінювання. Дана робота направлена на контроль просторових параметрів лазерного випромінювання за рахунок внесення зміни у розрахунковий емпіричний коефіцієнт. Проведення досліджень з імпульсним випромінюванням та з різними типами металів, що дозволило у достатній мірі розібрати природу нестабільності лазерного випромінювання.

Наукова новизна роботи заключається у вдосконаленні системи контролю шляхом зменшення розбіжності лазерного випромінювання під час контакту із зварювальною поверхнею. Більш наближений теоретичний опис процесу лазерного зварювання дає можливість збільшити точність напрямлення випромінювання.

Сьогодні постає дві основні проблеми при лазерному зварюванні. Це стабільність температурна та просторова лазерного випромінювання. Велику увагу приділяють температурній нестабільності. Вже існує 


\section{$\underline{2}$ АВТОМАТИЧНІ ТА АВТОМАТИЗОВАНІ СИСТЕМИ УПРАВЛІННЯ ТЕХНОЛОГІЧНИМИ ПРОЦЕСАМИ}

декілька способів вирішення даної проблеми. Проте відносно мало робіт присвячені просторовій нестабільності лазерного випромінювання.

Причиною того можуть бути декілька пунктів. Зокрема це:

А) короткочасність імпульсу лазерного випромінювання,

Б) нестабільність потужності установки генерування лазерного випромінювання,

В) фактори навколишнього середовища (середа проходження імпульсу, вологість і температура у приміщенні та ін.).

Таким чином, для проведення дослідів або слід враховувати усі параметри, або створити умови, в яких ці параметри не матимуть впливу на результат чи відсутні.

Аналізуючи праці та проведені дослідження в області лазерних технологій, слід зазначити, що більшість робіт присвячена моделюванню процесу лазерного імпульсного зварювання, для зменшення дефектів зварювального шва.

Розглянувши параметри лазерного випромінювання можна сказати, що діапазон застосування лазерів дуже великий. Потужні лазери, з точним наведенням променя широко застосовуються у промисловості, зокрема для різання, термообробки та зварювання матеріалів. Виходячи із характеристик твердотілих лазерів слід сказати, що на даному етапі розвитку науки і техніки їх застосування зменшується по відношенню до газових.

Через складний економічний стан країни на державних підприємствах застосовуються лазерні установки зразків кінця вісімдесятих років минулого століття, тому подальша модернізація таких установок надає ще $\mathrm{i}$ виграш в економічному плані.

Проведене дослідження геометричних параметрів поверхні фокальних точок при імпульсному лазерному випромінюванні установки лазерного зварювання. Задля подальшого виключення великих розбіжностей при заданих параметрах розсіювання лазерного випромінювання установки лазерного зварювання.

Метою роботи є автоматизація процесів налаштування режимів лазерного зварювання криволінійних деталей на основі врахування фізичних процесів в установці для лазерного зварювання, зокрема параметрів опто-механічного блоку, властивостей використовуваного лазерного випромінювання та 3 урахуванням характеристик матеріалів.

Об’єктом дослідження є процес лазерного зварювання матеріалів.

Предметом дослідженняє оптимізація режимів лазерного зварювання сплавів металів.

Для проведення дослідів було обрано два типи металевих пластин:

А) пластина із матеріалу: сталь-3;

Б) пластина із матеріалу: алюміній, відсотковий вміст алюмінію - 95 відсотків. (Рисунок 1)

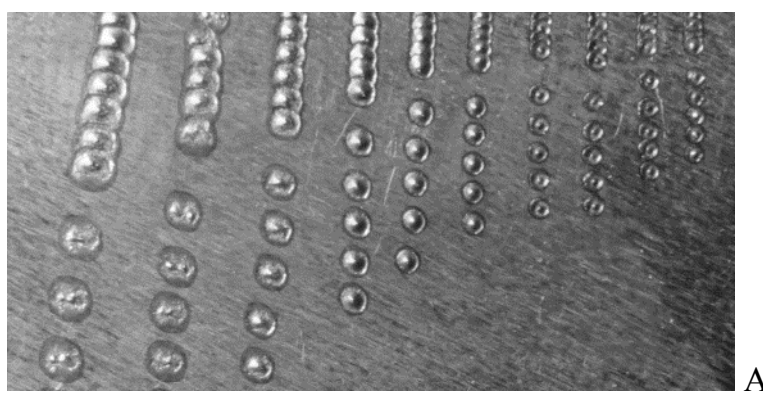

Б)

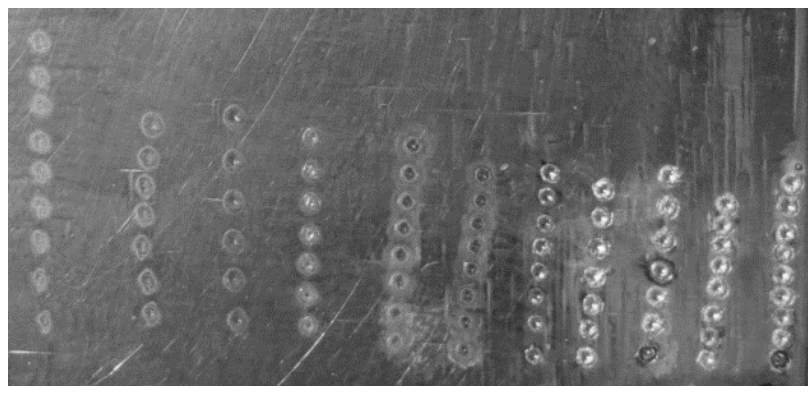

Рис. 1 - Металеві пластини після проведення досліджень А) сталь-3; Б) алюміній-95 


\section{$\underline{2}$ АВТОМАТИЧНІ ТА АВТОМАТИЗОВАНІ СИСТЕМИ УПРАВЛІННЯ ТЕХНОЛОГІЧНИМИ ПРОЦЕСАМИ}

Метрологічні характеристики металевих пластин визначені у Таблиці 1.

Таблиця 1. - Геометричні розміри та лінійно-кутові параметри досліджуваних металічних пластин

\begin{tabular}{|c|c|c|c|}
\hline Матеріал & Геометричний параметр & $\begin{array}{c}\text { Числове значення } \\
\text { параметру }\end{array}$ & $\begin{array}{c}\text { Допустима сумарна } \\
\text { похибка }\end{array}$ \\
\hline 1 & 2 & 3 & 4 \\
\hline \multirow[t]{5}{*}{ Сталь-3 } & Ширина & $40,3 \mathrm{MM}$ & $0,1 \mathrm{MM}$ \\
\hline & Довжина & $60,0 \mathrm{MM}$ & $0,1 \mathrm{MM}$ \\
\hline & Висота & $2,4 \mathrm{MM}$ & $0,1 \mathrm{MM}$ \\
\hline & Неплоскістність & 2мкм & 0,1 мкм \\
\hline & Шорохуватість & $\nabla 7$ & $5 \%$ \\
\hline \multirow[t]{5}{*}{ Алюміній } & Ширина & $56,0 \mathrm{MM}$ & $0,1 \mathrm{MM}$ \\
\hline & Довжина & $65,0 \mathrm{MM}$ & $0,1 \mathrm{MM}$ \\
\hline & Висота & $8,5 \mathrm{MM}$ & $0,1 \mathrm{MM}$ \\
\hline & Неплоскістність & 4мкм & $0,1 \mathrm{мкм}$ \\
\hline & Шорохуватість & $\nabla 6$ & $14 \%$ \\
\hline
\end{tabular}

Перед проведенням дослідів розрахуємо теоретично який мінімальній розмір фокальної плями ми можемо отримати при ідеальному фокусуванню оптичної установки із заданими параметрами.

Для розрахунку діаметра фокальної плями, з урахуванням розсіювання лазерного випромінювання та абераціями, використовуємо наступну формулу:

$$
\mathrm{d}_{\mathrm{n}}=\mathrm{d}_{\mathrm{w}}+\mathrm{d}_{\mathrm{a}}
$$

Складова $\mathrm{d}_{w}$ - обумовлена розсіюванням лазерного випромінювання та визначається як:

$$
\mathrm{d}_{\mathrm{w}}=\mathrm{F} * \mathrm{~W}
$$

в свою чергу F - фокусна відстань лінзи, W - кут розсіювання лазерного випромінювання. Який визначаємо наступною залежністю:

$$
\mathrm{W}=\frac{1.22 \lambda}{\mathrm{t}}
$$

В формулі $\lambda-$ довжина хвилі лазера, $\mathrm{t}=\frac{\mathrm{D}-\mathrm{d}_{\mathrm{b}}}{2}-$ ширина кільця лазерного випромінювання. Параметр $\mathrm{t}$ використовується для розрахунків, при використанні нестійкого телескопічного лазерного резонатору, 3 технічного опису установки видно, що при встановленні негативного елементу оптичної системи лазер перетворюється на нестійкий телескопічний резонатор з коефіцієнтом посилення $\mathrm{M=2}$ або $\mathrm{M=4}$.

Складова $\mathrm{d}_{\mathrm{a}}$ - обумовлена наявністю аберацій та визначається наступним чином:

$$
\mathrm{d}_{\mathrm{a}}=\frac{\mathrm{P}^{\cdot} \mathrm{D}^{3}}{\left(32 \mathrm{~F}^{2}\right)}
$$

Де $\mathrm{P}^{\star}$ - параметр, що визначає частину потужності випромінювання, яка міститься у куті дифракції на різних оптичних поверхнях, F - фокусна відстань лінзи, D - діаметр променю, що виходить із резонатора, тобто діаметр активного елементу лазера.

Врахувавши формули (2) та (3) можемо записати вираз (1) наступним чином:

$$
\mathrm{d}_{\mathrm{n}}=\mathrm{F} \frac{1.22 \lambda}{\mathrm{D}}+\frac{\mathrm{P} \cdot \mathrm{D}^{3}}{\left(32 \mathrm{~F}^{2}\right)}
$$




\section{2 АВТОМАТИЧНІ ТА АВТОМАТИЗОВАНІ СИСТЕМИ УПРАВЛІННЯ ТЕХНОЛОГІЧНИМИ ПРОЦЕСАМИ}

Про диференціювавши по F та прирівнявши до нуля вираз (4) можемо отримати вираз для розрахунку оптимальної фокусної відстані, що забезпечить мінімальний розмір фокальної плями:

$$
\mathrm{F}_{\mathrm{onT}}=0.37 \mathrm{D} \sqrt[3]{\frac{\mathrm{p}^{-t}}{\lambda}}
$$

Таким чином, якщо підставити формулу (4) у формулу (5), то отримаємо вираз для розрахунку діаметра мінімальної фокальної плями:

$$
\begin{gathered}
d_{n \min }=0.67 \mathrm{D} \sqrt[3]{\mathrm{P}^{-}\left(\frac{\mathrm{A}}{\mathrm{t}}\right)^{2}} \\
\mathrm{~d}_{\mathrm{n} \min }=0.67 * 6.3 * \sqrt[3]{53.338} * \sqrt[3]{\left(\frac{0.001064}{1.575}\right)^{2}}=4.221 * 3.764 * 0.008=0.122 \mathrm{MM}
\end{gathered}
$$

Відобразимо отримані результати для різних металевих пластин при зміні коефіцієнта розсіювання та температурного коефіцієнта на графіках.
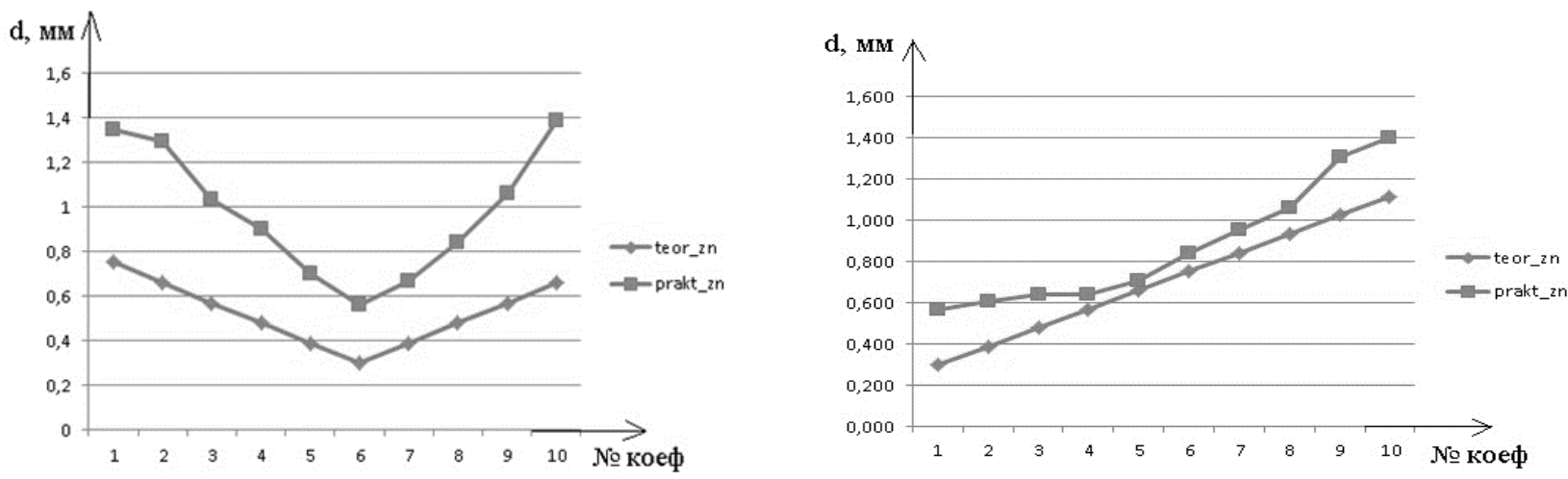

Рис. 2 - Результати експериментів для пластини СТАЛЬ-3

А) зміна коефіцієнта розсіювання; Б) зміна температурного коефіцієнта та коефіцієнта розсіювання
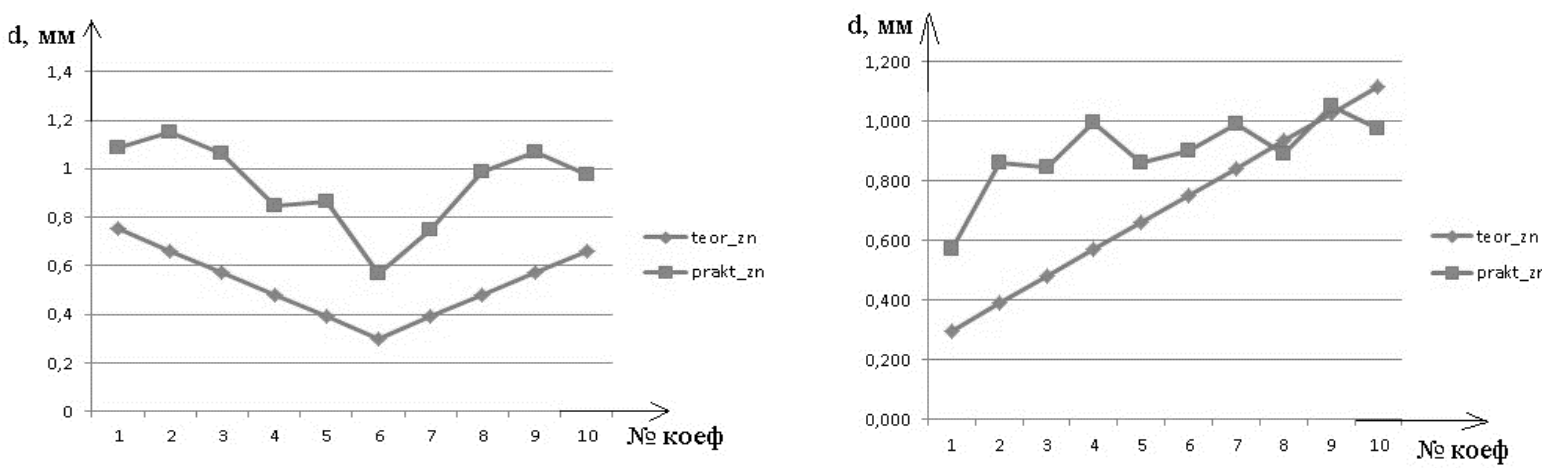

Рис. 3 - Результати експериментів для пластини АЛЮМІНІЙ

А) зміна коефіцієнта розсіювання; Б) зміна температурного коефіцієнта та коефіцієнта розсіювання

Як бачимо результати проведених досліджень не відображають теоретично розрахованих результатів. Тому пропонуємо ввести модифікований емпіричний коефіцієнт для розрахунку діаметру фокальної плями:

$$
\varepsilon=\frac{1,22 * \mathrm{M}}{1-1 / \mathrm{M}}
$$

Відобразимо отримані результати у вигляді графіків. 


\section{$\underline{2}$ АВТОМАТИЧНІ ТА АВТОМАТИЗОВАНІ СИСТЕМИ УПРАВЛІННЯ} ТЕХНОЛОГІЧНИМИ ПРОЦЕСАМИ

А) зміна коефіц̧ієнта розсіювання; Б) зміна температурного коефіцієнта та коефіцієнта розсіювання
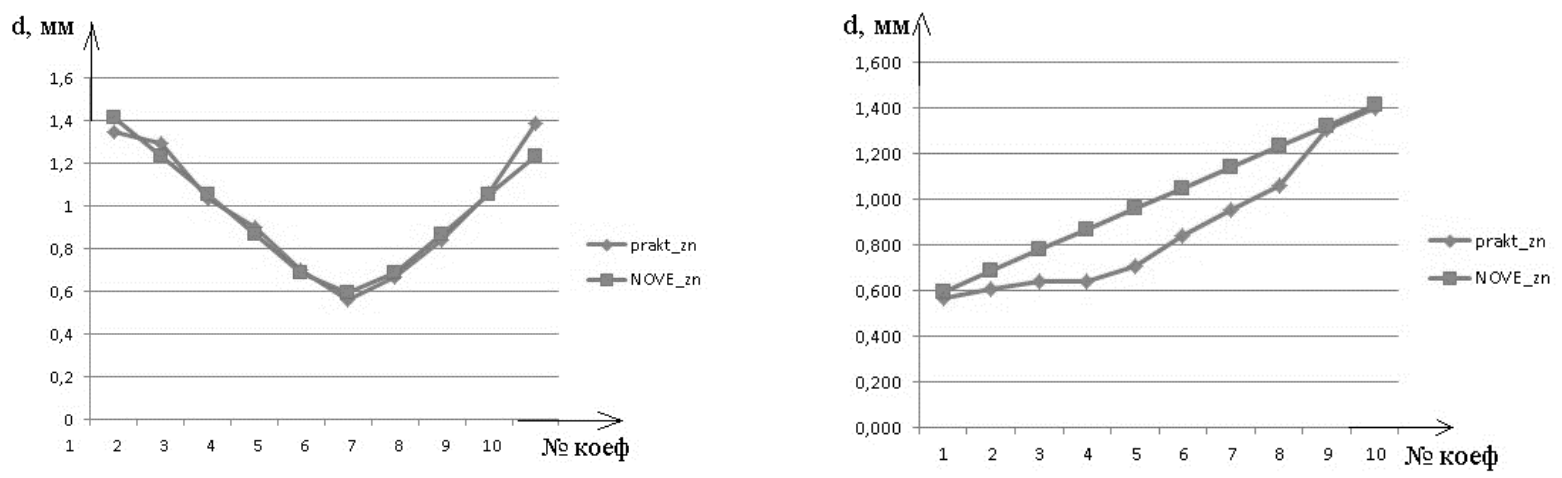

Рис. 4 - Відповідність результатів проведених досліджень у порівнянні з теоретично розрахованими значеннями, з урахуванням модифікованого емпіричного коефіцієнта, СТАЛЬ-3
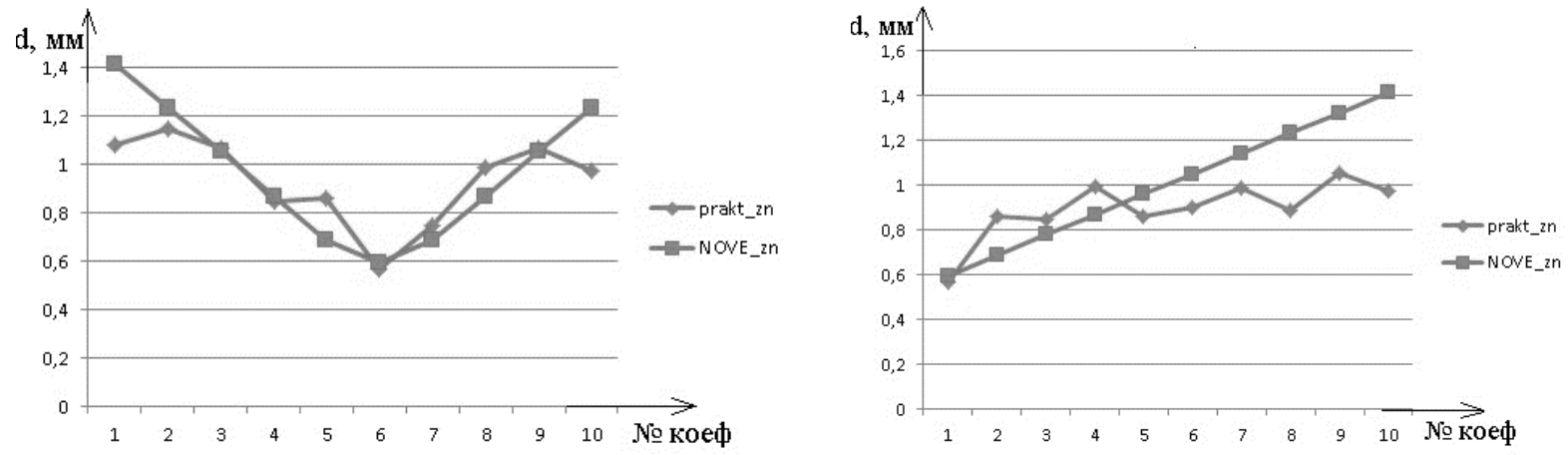

Рисунок 5 - Відповідність результатів проведених досліджень у порівнянні з теоретично розрахованими значеннями, з урахуванням модифікованого емпіричного коефіцієнта, АЛЮМІНІЙ

А) зміна коефіцієнта розсіювання; Б) зміна температурного коефіцієнта та коефіцієнта розсіювання

Проведена робота по дослідженню просторових параметрів лазерного випромінювання дає змогу точніше оцінювати просторове розсіювання, поглинання енергії випромінювання тим самим приводячи нас до:

- Спрощення процесу моделювання лазерного зварювання металів;

- Врахуванню перетворень при підборі оптимального режиму зварювання;

- Можливості розробки блоку керування шириною шва при зварюванні;

- Оптимізації процесу лазерного зварювання;

- Зменшення впливу оператора на процес зварювання.

Виділена функціональна залежність дає можливість розробити принципово нову технічну документацію на використання установки «Квант-15». Збільшити спектр робіт на даній установці, покращити точність тим самим модернізувати установку до належного рівня сьогодення.

Також у роботі встановлено:

- Кількісну залежність параметрів зварювального шва від режимів роботи установки;

- Підведено теоретичну базу під фізичні процеси, що відбуваються при лазерному зварюванні різних типів сплавів; 


\section{2 АВТОМАТИЧНІ ТА АВТОМАТИЗОВАНІ СИСТЕМИ УПРАВЛІННЯ ТЕХНОЛОГІЧНИМИ ПРОЦЕСАМИ}

- Практична цінність результатів роботи полягає у наданні можливості автоматизації процесу налаштування режимів зварювання;

- Передбачуванність результатів зварювання забезпечує підвищення якості і надійності зварювального шва, що вкрай важливо при виготовленні прецизійного обладнання спеціального призначення.

Література:

1. Установка лазерной сварки, резки и термообработки «КВАНТ-15», Техническое описание и инструкция по эксплуатации ТДМ2.334.000ТО, Редакция 1-81. - 24c, ил;

2. Григорьянц А.Г., Шиганов И.Н. Лазерная сварка металлов. «Высшая школа», 1978р. - 216с, ил;

3. Коротеев Н.И.. Физика мощного лазерного излучения. «Наука». М.,1991г. - 507 с, ил;

4. Баранов М.С., Вощинский М.Л., Гейринхс И.Н. Лазерная сварка металлов. Машиностроение, 1979 г. $52 \mathrm{c}$;

5. А.С. Борейшо. Лазеры: устройство и действие. Учебное пособие, Санкт-Петербург, 1992г. - 216с;

6. Григорьянц А.Г.. Основы лазерной обработки материалов. Москва «Машиностроение», 1989 г. - 302 с, ил.

\section{ध НОВОСТИ АВТОМАТИЗАЦИИ}

\section{Источник энергии для автономных датчиков с WiFi или ZigBeе}

Нелегко найти зарядное устройство небольшого размера, использующее энергию ветра, которое бы действительно работало. Действительно, довольно сложно пропустить достаточное количество ветра сквозь небольшую штуковину. Но теперь, благодаря компании Humdinger Wind Energy LLC и разработанному ей устройству под названием MicroBelt, кое-что может измениться. Это пьезоэлектрическая система, предположительно в 10 раз более эффективная в плане сбора энергии, чем аналогичные устройства такого же размера.

Это небольшое устройство способно собирать энергию порывов ветра скоростью всего 3 метра в секунду

Humdinger начала свою работу всего с 6 сотрудниками в штате - они и разработали новый способ сбора энергии ветра при помощи небольших устройств. В системе используется аэроупругий «язычок» и вибрация мембраны - именно это, а не вращение турбины является сердцем устройства MicroBelt, которое должно заменить батареи в беспроводных сетях датчиков. Поток воздуха будет использоваться, чтобы обеспечивать передатчики энергией, а нужда в установке более дорогих аккумуляторов пропадет сама собой. И, поскольку новая система работает без вращающихся деталей, ожидается, что срок ее службы составит 20 лет.

Новое устройство является одновременно недорогим и эффективным. Энергия начинает вырабатываться от порывов ветра со скоростью всего 3 метра в секунду. А если сила ветра достигнет 5,5 м/с, выработка электроэнергии составит 2мВт. Помимо эффективности, еще одним преимуществом данной системы является низкая стоимость изготовления, обусловленная тем, что используемые материалы очень просты. Представители компании Humdinger говорят о таких применениях своей разработки, как системы слежения за зданиями и и системы контроля дорожного движения - на самом деле, годится практически любое место, где есть достаточно сильный ток воздуха и установлены устройства, пока использующие в своей работе аккумуляторы. 